\title{
O espaço fabril enquanto lugar da memória
}

\section{Eloisa Dezen-Kempter ${ }^{1}$}

IFCH-UNICAMP

\section{Resumo}

As cidades passam por uma ampla adaptação aos novos processos econômicos e tecnológicos, que tiveram um impacto profundo sobre o ambiente construído, principalmente sobre as paisagens industriais. Essas paisagens representam uma porção significativa do espaço urbano em cidades industriais, que foi consolidado ao longo do século 20 até a década de 70. A incorporação dessas estruturas industriais, como foi o caso da Fábrica Santa Amélia, ao acervo de bens culturais protegidos em caráter nacional pelo IPHAN, marca uma mudança, ainda que incipiente, no tratamento dado à construção identitária dos lugares de memória selecionados por esse órgão.

Palavras-chave: lugares de memória, patrimônio industrial, Fábrica Santa Amélia

\begin{abstract}
Cities call for a broad adaptation to new economic and technological processes, which had a deep impact on the built environment, especially on the industrial landscapes. These landscapes represent a significant fraction of urban space in industrial cities, which was consolidated during the 20th century until the 70th. The incorporation of these industrial structures, like the Factory Santa Amelia, in the roll of cultural heritage protected in national level by the IPHAN, marks a change, albeit incipient, in the treatment of the identity construction of places of memory selected by this Organization.
\end{abstract}

Key-words: memory places, industrial heritage, Factory Santa Amélia

\footnotetext{
1 Arquiteta, mestre em Urbanismo Europeu pela BAUHAUS-WEIMAR, doutorando pelo IFCHUNICAMP, área de concentração Política, Memória e Cidade.
} 


\section{A memória e seu espaço}

O espaço fabril no apogeu industrial foi o núcleo de máximo prestígio no tecido urbano. O caráter simbólico imbuído em suas formas e sua arquitetura, enquanto processo de construção identitária, é perpetuado pela preservação, na medida em que ela transforma esses locais em monumentos da memória.

O historiador Pierre Nora denominou estes espaços de "lugares da memória". Segundo Nora, os traços que definem tais lugares são numerosos e complexos: "não são aquilo que nos lembramos, mas lá onde a memória trabalha: não propriamente a tradição, mas seu laboratório"2. Portanto, esses lugares representam os frutos de uma vontade e de um desejo "de bloquear o trabalho do esquecimento, de fixar um estado de coisas, de imortalizar a morte, de materializar o imaterial para [...] fixar o máximo de sentidos dentro de um mínimo de sinais" ${ }^{3}$ ou seja, concretizam espacialmente ideologias sociais, políticas, religiosas e raciais.

A alusão à terminologia "Lugar de memória"4 de Pierre Nora, para definir as unidades fabris selecionadas pelo IPHAN, é proposta dentro do mesmo objetivo definido por este, ao cunhar o termo como uma nova categoria de inteligibilidade histórica contemporânea, que tinha por objetivo definir, teorizar e confinar a noção de lugar de memória dentro de um campo específico. Nora empresta do De oratore de Cícero o termo locus memorie, na qual se associa a um lugar uma idéia, transformando-o em um símbolo. Assim, Nora define Lugar de Memória como toda "unidade significativa, de ordem material ou ideal, da qual a vontade dos homens ou o trabalho do tempo fez um elemento simbólico do patrimônio da memória de uma comunidade qualquer" ${ }^{\prime 5}$

\footnotetext{
2 NORA, Pierre. Lieux de mémoire, I-II-III. Paris: Gallimard, "Quarto", 1997, p.35.

3 idem ibidem.

4 Lieux de mémoire é uma publicação iniciada em 1984 com o primeiro tomo intitulado La Republique, em 1986 são publicados mais três volumes pertencentes ao segundo tomo denominado La Nation e em 1993 são publicados mais três volumes do terceiro tomo: Les France.

5 Pierre Nora, Les France, tomo 1, p.20 apud Enders Armelle, Estudos históricos, Rio de Janeiro, vol. 6 no11, p.129.
} 
Nos sete volumes da coleção esse lugar permeia o trabalho de Nora em uma geometria variável, designando ora objetos, ora um método, ora a memória, ora o trabalho dos historiadores.

Considerando-se aqui os espaços fabris, refletimos se a monumentalização, a partir da proteção legal via tombamento, consolida seu valor enquanto lugar de memória, com o papel de perenizar a identidade dos grupos sociais envolvidos neste processo.

\section{Patrimônio Industrial: por numa arqueologia da proteção}

A transição do século XX para o XXI propõe um leitura acerca da identificação, documentação, promoção e proteção do patrimônio cultural, de forma mais ampla e plural. Se durante décadas as políticas patrimoniais privilegiaram a proteção de monumentos que traduzissem uma imagem do Brasil, que segundo Silvana Rubino ${ }^{6}$ era quase que exclusivamente branca, senhorial e católica, agora saem da vacuidade de sentido histórico outros conjuntos arquitetônicos, como as fábricas, com seus modos de ocupação do território, seu saber fazer e as formas impostas de viver, e conquistam seu lugar na memória do Brasil.

Os anos de 1980 marcam a incorporação ao acervo material protegido pelo Instituto do Patrimônio Histórico e Artístico Nacional - IPHAN, de duas fábricas, sendo uma delas com seu maquinário incluído.

A iniciativa do órgão federal teve por objetivo valorizar a contribuição da indústria na composição do painel cultural brasileiro, reconhecendo a importância da participação econômica e cultural dos operários e empreendedores na formação social do país. Os novos bens tombados, somados aos poucos bens protegidos relacionados à prática industrial no Brasil ${ }^{7}$ desde a criação do IPHAN, ainda representam uma parcela muito pequena da riqueza e da complexidade da

\footnotetext{
${ }^{6}$ RUBINO, Silvana B. As fachadas da história. As origens, a criação e os trabalhos do SPHAN, 19361967. 1992. Mestrado em Antropologia Social. IFCH UNICAMP.

7 A fábrica de Ferro Patriótica e a Real Fábrica de Ferro São João de Ipanema foram tombadas respectivamente em 1938 e 1964, além de vários engenhos tombados nas primeiras décadas de funcionamento do IPHAN.
} 
indústria no país. Embora a atitude do IPHAN possa ser vista como positiva ao valorizar o patrimônio cultural legado pela industrialização, ela corroborou com a visão seletiva do Instituto na seleção regional dos bens, ao tombar duas fábricas, uma em São Luiz e outra em João Pessoa.

Ressalta-se também o papel de São Paulo e Rio de Janeiro na industrialização brasileira que ainda não mereceram, por parte do IPHAN, um olhar mais acurado e profundo na medida em que tais estados compõem o mais rico legado cultural brasileiro edificado relacionado com a indústria.

Ao avaliar o tombamento da Fábrica Santa Amélia em São Luís, tomaremos emprestadas as ordens de valores que Ulpiano Bezerra de Menezes ${ }^{8}$ atribui ao considerar o patrimônio ambiental urbano: cognitivo, formal, afetivo e pragmático, que achamos pertinentes para avaliação do lugar memorial dos espaços fabris.

O valor cognitivo está associado à possibilidade de conhecimento através de suas mais variadas formas, referindo-se à informação vinculada pelo objeto, que no caso do patrimônio industrial só pode ser alcançado em sua plenitude se for levado em conta o processo produtivo.

O valor formal diz respeito às suas virtudes estéticas, que segundo Menezes não se refere àquele "sentido universal, mas a sua capacidade de potenciar a 'percepção sensorial'". Essa capacidade vai ser confirmada pelos ícones da arquitetura fabril enquanto elementos de forte apelo sensorial, conforme podemos constatar no relato de Henri-Pierre Jeudy:

Quem não sente ainda grande emoção ao passear por áreas industriais abandonadas, fábricas desocupadas, ou portos onde gruas enferrujam, ou por estações desativadas? Uma emoção estranha, uma vez que não está necessariamente relacionada, como freqüentemente se acredita, à nostalgia de uma outra época. Nossa "boa" consciência, por outro lado, nos coloca em estado de alerta: como podemos sentir saudade de um tempo que nossos antepassados eram condenados a horas de trabalho intensivo, em condições sanitárias difíceis? O silêncio desses territórios abandonados, dessas construções desmoronadas, nos coloca, contudo, em um estado de alucinação, uma vez que podemos ver os corpos, escutar vozes e gritos, ter a sensação de uma atmosfera de

\footnotetext{
8 MENESES, Ulpiano T. Bezerra de. Patrimônio ambiental urbano: do lugar comum ao lugar de todos. Revista C J Arquitetura, Rio de Janeiro, n. 19, p. 45-46, 1978.
} 
vida comum que a literatura e o cinema nos sugerem o tempo todo. Um estado visionário, retrospectivo, que nos incomoda [...] (JEUDY, 2005, p.25)."

Os valores afetivos incluem as relações subjetivas do indivíduo em sociedade, embutidas aí todas as cargas simbólicas identitárias de pertencimento. Essa categoria de valor está diretamente ligada à necessidade da comunidade, em perpetuar o significado original dos monumentos, que caracterizam os grupos minoritários da sociedade, como os próprios operários, no caso das fábricas, que passaram a criticar a composição unitária e excludente adotada durante décadas com relação à feição do patrimônio brasileiro protegido pelo IPHAN.

Os valores pragmáticos, segundo Menezes, são aqueles que se prestam ao uso altamente qualificado ou a criação tecnológica.

Dentro dessa perspectiva, a valorização do patrimônio histórico edificado através das políticas de proteção de bens culturais do país, apesar de seu aspecto ainda restrito, deu um passo importante com o tombamento da Fábrica Santa Amélia, em São Luiz no Maranhão, no bojo do enfoque do registro, referência e proteção de áreas urbanas de interesse cultural, dentro das quais o patrimônio edificado da industrialização representa um elemento significativo, parte de um conjunto de edificações plurais, portadores de valores simbólicos e memorias.

Avaliar o processo de proteção da Fábrica Santa Amélia, a partir dos pareceres dos documentos de trabalho do IPHAN, justifica-se na colocação de Cecília Rodrigues dos Santos ${ }^{9}$ :

[...] embora os pareceres estejam talvez entre os documentos mais corriqueiros no cotidiano de uma repartição pública, eles acabaram por se tornar também importantes depositários da memória do seu trabalho $2^{10}$.

\footnotetext{
${ }^{9}$ SANTOS, Cecília H.G. Rodrigues dos. Problema mal posto, problema reposto. In: Nobre, A. L.; Kamita, M.; Leonídio, O.; Conduru, R.. (Org.). Lucio Costa - um modo de ser moderno. São Paulo: Cosac Naify, 2004, p. 132-145.

${ }^{10}$ Idem, p.133.
} 
Santos enfatiza a aplicabilidade da leitura sistemática das correspondências trocadas entre técnicos do IPHAN, entre estes e seus interlocutores, e de pareceres provocados por circunstâncias de trabalho diversas, mesmo que sob a forma de ofícios e memorandos escritos sob o emblema da República, para a transparência "dos critérios técnicos adotados para os tombamentos e as discussões que os acompanharam", esclarecendo também "o processo que acabou por delinear, mesmo que de forma não sistematizada, o corpo conceitual que embasou a ação da Instituição e o papel de cada um de seus atores"(SANTOS, 2004, p.133).

Maria Cecília Londres Fonseca refere-se aos processos de tombamento como "verdadeiros dossiês" que nos permitem analisar a prática da política de proteção federal dos bens culturais no Brasil e avaliar suas implicações nos sentidos da preservação para os diferentes atores sociais envolvidos (FONSECA, 2005, p.181).

No processo de tombamento da Fábrica Santa Amélia fica muito claro essa dialética, a partir da análise dos critérios de atribuição de valor artístico e histórico ao edifício por parte dos agentes oficiais e as reações do proprietário do imóvel, através do questionamento tanto do valor atribuído ao imóvel, como das restrições impostas ao bem, e na sua visão, extendida também à cidade, pelo intituto do tombamento.

O questionamento sobre a legitimidade do processo de atribuição de valor aos bens, não é somente um processo unilateral por parte do proprietário do bem afetado, mas é também uma reflexão por parte dos técnicos do IPHAN, principalmente para bens até então não consagrados pela Instituição, como é o caso do patrimônio arquitetônico relacionado à indústria. Essa questão é levantada no parecer da arquiteta Dora Alcântara, então responsável pela Seção de Tombamentos da DTC, sobre o processo de tombamento do Farol de Macuripe em Fortaleza, Ceará (no 1072-T-82), arquivado pelo IPHAN:

Sempre que nos é proposta a preservação de um bem tradicional em nossa prática institucional de tombamento - igreja, teatro etc. - não há dificuldade maior, porque já possuímos o necessário quadro de exemplos para referenciá-lo. Se, ao contrário, a proposta refere-se a um objeto não tradicional - caixa d'água, vila 
operária etc. - temos necessidade de organizar um mínimo quadro de referência para opinar com menor margem de erro ${ }^{11}$.

Ainda com relação à atribuição de valores, Fonseca observa o problema no critério de inscrições nos livros do tombo, pois o tipo de inscrição condiciona não só a leitura do bem como também o modo como será conservado:

É difícil entender, por exemplo, por que a Caixa d'água de Pelotas, RS, cujo caráter pioneiro é referido por documentos, está inscrita apena no Livro de Belas Artes, enquanto o Reservatório de Mocó, Amazonas, mais recente tem dupla inscrição (Livro Histórico/Livro de Belas Artes); por que o Açude do Cedro, CE, que, além de obra notável de arquitetura, foi a 'primeira rede de canais de irrigação levada a efeito no Brasil', não está inscrito também no Livro Histórico; porque o Porto de Manaus, testemunho inconteste do ciclo da borracha, foi inscrito apena no Livro de Belas Artes e no Livro Arqueológico Etnográfico e Paisagístico, enquanto o Teatro Amazonas, de inegável valor artístico, havia sido inscrito apenas no Livro Histórico ${ }^{12}$.

O mesmo se aplica às edificações da antiga Fábrica Santa Amélia, que foi inscrita somente no Livro Histórico, sendo que seu valor enquanto exemplar arquitetônico do período industrial é enfaticamente abordado na análise do tombamento como veremos a seguir.

\section{A Fábrica de Tecidos Santa Amélia}

A edificação da Fábrica Santa Amélia abrigou, a princípio, a Companhia de Lanifícios Maranhense, instalada em 1892 e que funcionou por 10 anos, até sua falência. Em 1902, as instalações da fábrica e seu maquinário foram arrematados em leilão pelo empresário Cândido José Ribeiro, e, somados à Fábrica São Luís, passaram a constituir o Cotonifício Cândido Ribeiro, que recebeu o nome comercial de Fábrica Santa Amélia. A Fábrica funcionou por 64 anos (de 1902 a 1966), e constituiu marco importante na história das indústrias maranhenses. O nascente parque manufatureiro do Maranhão, no final do século XIX, concentrouse em São Luís, e em 1895 era composto por 27 fábricas, sendo 14 delas

\footnotetext{
${ }^{11}$ FONSECA, Maria Cecília Londres da. O patrimônio em processo: trajetória da política federal de preservação no Brasil. Rio de Janeiro, Editora UFRJ; MInC-IPHAN, 2005.p.202.

12 Idem, p.205.
} 
têxteis ${ }^{13}$. O algodão representou, durante décadas no século XIX, fonte de lucros para a economia do Maranhão, cuja produção encontrou condições altamente propícias para desenvolver-se e capitalizar-se, devido à guerra de independência dos EUA e logo em seguida pela revolução industrial inglesa, fornecendo matériaprima para o mercado externo e para suprir o mercado interno de tecidos.

O pedido de tombamento das edificações da Fábrica Santa Amélia, referente ao processo n⿳01144-T-85 do IPHAN, foi apresentado na $121^{\text {a }}$ reunião do Conselho Consultivo do Patrimônio Histórico e Artístico Nacional, realizada em 10 de julho de 1987, sendo aprovado por unaminidade.

O prédio da Fiação e Tecelagem de algodão Santa Amélia, conforme relato do conselheiro Roberto Cavalcanti de Albuquerque, baseado nos pareceres da Arquiteta Dora Alcântara, trata-se "de exemplar significativo da arquitetura industrial do Maranhão, representando, com fidelidade, a simbiose que muitas construções industriais do Brasil da época revelam, de construção residencial com a industrial"14.

Esse tombamento marca a inclusão, no livro de Tombo da Nação, de um exemplar referente a um espaço de produção. Embora o processo tenha ocorrido de forma rápida (1985 a 1987), alguns percalços e questionamentos aconteceram, demonstrando que o patrimônio industrial ainda não foi incorporado enquanto forma representativa digna da herança cultural do Brasil. O pedido de tombamento pauta-se pelo valor histórico e arquitetônico da Fábrica Santa Amélia.

A justificativa de seu valor histórico está no fato dessa Fábrica representar o processo de industrialização maranhense iniciado em meados do século XIX, com a instalação de inúmeras fábricas de tecelagem e fiação, explorando a cultura algodoeira local. A fábrica Santa Amélia foi responsável por grande parte da produção de tecidos do estado, tanto para o mercado interno quanto externo, produzindo uma variedade de cerca de 24 tipos de tecidos, em maquinário

\footnotetext{
13 VIVEIROS, Jerônimo de. História do Comércio do Maranhão, 1612-1895. São Luís, Edição da Associação Comercial do Maranhão, $2^{\circ}$ vol.p.558-559.Apud CAMPOS, M. H. Farrapos de algodão: observações acerca da economia maranhense na primeira metade do século XX. Revista de Economia Política e História Econômica, São Paulo, p. 05 - 26, 01 jun. 2008, p.8.

14 Ata da $121^{a}$ reunião do Conselho Consultivo do Patrimônio Histórico e Artístico Nacional, realizada em 10 de julho de 1987. IPHAN, Processo de Tombamento n01144-T-85, p.64.
} 
totalmente de origem inglesa. A fábrica foi, ainda, uma grande empregadora, chegando a possuir, em 1941, 300 funcionários, e atuou mais de meio século na fabricação de fios e tecidos de algodão. (IPHAN, Processo no 1144-T-85, p.17).

O valor arquitetônico é atribuído ao imóvel pela sua notável arquitetura industrial maranhense, conforme relato do Eng. Carlos Danúzio de Castro e Lima:

Construído em pedra cal e tijolo, apresentando inicialmente partido quadrangular de dois pavimentos, mirante com cobertura de telha de barro tipo canal, e estrutura metálica para vencer grandes vãos, o prédio reproduz os esquemas da arquitetura industrial adotados no período da industrialização no Maranhão. Ao ser adquirido, por ocasião da instalação da fábrica, teve seu sistema estrutural reforçado com a introdução de elementos metálicos, e seu espaço ampliado com a construção de dois acréscimos laterais térreos, também em estrutura metálica, modulada, importada da Inglaterra, e cobertura em telha de barro tipo Marseille. A fachada, resultada da construção em várias épocas, guarda, entretanto, uma distribuição harmoniosa, simétrica, tendo o corpo central, como já foi assinalado, dois pavimentos e mirante, recobertos de azulejos portugueses, e terminando em beiral. Quanto aos corpos laterais, tem revestimento em cal, areia e barro, e são terminados em platibanda de elementos vazados. As janelas e portas possuem verga em arco abatido. No segundo pavimento as janelas são providas de balcões sacados feitos de ferro forjado, sendo que as três centrais têm balcão corrido, e as demais, balcões individuais. Internamente, em sua parte central, o térreo apresenta compartimentos ligados por grandes arcos, piso de cimento, presumivelmente, cobrindo a pedra de cantaria. Próximo à porta principal, notável escada de metal em caracol, de origem inglesa, leva ao segundo pavimento onde o piso é de assoalho e o forro de madeira. O acesso ao mirante é feito através de uma escada de madeira. Este se compõe de duas salas e sótãos laterais. O terreno situado atrás é revestido de paralelepípedos possuindo um grande poço do qual era retirada água que servia ao prédio,e uma chaminé de tijolo refratário de aproximadamente $28 \mathrm{~m}$ de altura $8^{15}$.

O engenheiro, responsável pelo parecer sobre o tombamento, afirma ainda, que embora a fábrica tenha sido desativada em 1966, dezenove anos antes do início do processo de tombamento, as adaptações que foram realizadas, em função de novas utilizações do imóvel, não resultaram, até aquele momento, em descaracterizações de ordem estrutural ou de sua espacialidade.

${ }^{15}$ Relatório Técnico. IPHAN, Processo de Tombamento no 1144-T-85, p.18. 
E finaliza seu relato, insistindo na necessidade do tombamento, pois o imóvel da fábrica encontra-se em situação vulnerável, por não encontrar-se na área de tombamento federal do conjunto de São Luiz, embora na zona de interesse histórico e vizinho da Fonte das Pedras, monumento incorporado ao patrimônio Municipal, podendo ser descaracterizado em função dos usos atuais.

Quanto ao seu valor arquitetônico, a arquiteta Dora Alcântara faz uma comparação do edifício da fábrica com os edifícios industriais construídos na mesma época, valendo-se da descrição de Nestor Goulart ${ }^{16}$, aludindo ao caráter nacional do fenômeno da construção industrial e das particularidades do gosto arquitetônico regional, no caso da fábrica Santa Amélia, os azulejos portugueses de padrão e colorido comuns aos grandes sobrados de função residencial do Maranhão.

A analogia entre a edificação fabril e edificações residenciais é novamente comparada pela arquiteta Dora Alcântara, a partir de elementos construtivos ou de composição do conjunto arquitetônico da Fábrica Santa Amélia, destacando sempre os comentários do professor Nestor Goulart:

1) As vergas da janelas da Fábrica Santa Amélia, em forma de arcos de círculo, desvinculadas das obreiras e com chaves enfáticas nos arcos: "as preocupações arquitetônicas [das fábricas] encaminhavam-se no mesmo sentido que as residências, concentrando-se em detalhes das janelas, de acordo com estilos em voga";

2) O Beiral da Fábrica ocultar o recorte das múltiplas águas do telhado, e a platibanda vazada nos corpos mais baixos da edificação: "os telhados ocultavamse sob platibandas avantajadas, de sorte que os conjuntos reduziam-se a retângulos alongados de tijolos por revestir enegrecidos pela fuligem, apenas interrompidos pelas janelas"(Goulart, 1978, p.85).

3) Os espaços internos apresentar uma organização que os adequava às funções industrias, com grandes vãos possibilitados pelo uso das estruturas metálicas, que permaneciam ocultas nas fachadas: "ainda que os interiores fossem por

\footnotetext{
${ }^{16}$ Goulart refere-se a similaridade entre as edificações industriais e o ambiente doméstido: "mesmo as indústrias, cujas condições de implantação e dimensões diferiam fundamentalmente de tudo o que então existira, adaptavam-se aos tipos tradicionais de relacionamento com os lotes. Ressentindo-se de compromissos de um passado recente com o ambiente doméstico, quer em sentido espacial quer em sentido social, acomodavam-se em galpões, com feições de residência, edificados em tijolos, sobre os limites das vias públicas" (GOULART, 1978, p.84)
} 
vezes montados com estruturas metálicas, as frentes, bem ou mal ocultavam tais soluções, organizando-se de modo que ofereciam às ruas aspecto tradicional"(Goulart, 1978, p.86).

4) A varanda doméstica, ventilada através das venezianas e das ripas alternadas do forro, em uma das alas do sobrado da casa.

Ao final da análise do pedido de tombamento, a arquiteta Dora Alcântara enfatiza a importância do inventário completo da fábrica como instrumento documental histórico para compreensão da dinâmica de produção:

Chamaríamos a atenção, como objeto de estudo complementar e para eventual processo de tombamento, o acervo desta fábrica (maquinário, arquivo, mostras de tecido, rótulos etc.) que poderão interessar aos pesquisadores da história da indústria no Brasil e, particularmente, a participação maranhense nessa história ${ }^{17}$.

Um aspecto relevante do patrimônio industrial, e do seu papel memorial enquanto testemunho de um saber fazer particular, no caso das edificações destinadas a atividades de produção, é que a simples preservação do edifício, representante da história da arquitetura industrial, muitas vezes com características regionais, como é o caso da Fábrica Santa Amélia, deixa a lacuna do processo industrial da modalidade de produção que o caracterizou enquanto representante de nossa herança da industrialização.

A preocupação do IPHAN, através da colocação da arquiteta. Dora Alcântara, corrobora o debate e discussões relacionados com a preservação do Patrimônio industrial, como a de Beatriz Kühl:

Para fundamentar essas análises é necessário desenvolver inventários sistemáticos alicerçados em processos cognitivos oferecidos pelas ciências humanas (história, sociologia, antropologia, geografia etc.), pois somente através desses intrumentos é possível ter uma compreensão suficientemente ampla do processo de industrilaização para avaliar o interesse de seus remanescentes - histórico, formal, memorial e simbólico para as comunidades - para identificar, de maneira consciente e

${ }^{17}$ IPHAN, Processo de Tombamento n¹144-T-85, p.22. 
embasada, os bens considerados merecedores de ser preservados para as gerações futuras.

[...] No que se refere ao inventário de bens arquitetônicos ligados às atividades produtivas, é necessário fazer um estudo históricodocumental e iconográfico, estudo analítico-descritivo e também comparativo, para entender as tipologias e transformação dos vários setores industriais ${ }^{18}$.

Vale destacar também o que a Carta de Nizhny Tagil sobre o patrimônio industrial estabelece na seção 5, como princípio de Conservação e Manutenção:

ii. A conservação dos sítios industriais requer um conhecimento profundo do objectivo ou objectivos para os quais foram construídos, assim como dos diferentes processos industriais que se puderam ali desenvolver. Estes podem ter mudado com 0 tempo, mas todas as antigas utilizações devem ser investigadas e avaliadas $^{19}$.

A análise pormenorizada das características e especificidades tanto do edifício quanto dos equipamentos fundamentaria um processo seletivo, que já foi concretizado na ação de tutela movido pelo IPHAN ao identificar o bem de interesse. A colocação da arquiteta Dora Alcântara, ao analisar as informações contidas no inventário, elaborado pela Divisão Regional do IPHAN no Maranhão, com relação ao acervo da fábrica Santa Amélia (documental e material), acaba sendo avaliada pelo diretor da DTC Augusto C. Da Silva Telles como objeto a parte, cabível a um novo processo de tombamento: "estamos também de acordo com a indicação do valioso acervo dessa fábrica como objeto de estudo e possível tema para novo processo de tombamento"20.

No que se refere ao processo de tombamento, aceita a indicação do bem a preservar, segue-se a fase de impugnação, na qual o proprietário contesta o tombamento.

\footnotetext{
${ }^{18}$ KÜHL, Beatriz M. Preservação do Patrimônio Arquitetônico da Industrialização. São Paulo: Ateliê Editorial, 2008, p. 46.

${ }^{19}$ Carta de Nizhny Tagil sobre o Património Industrial. The International Committee for the Conservation of the Industrial Heritage (TICCIH). Versão em português da Carta por Jose Manuel Lopes Cordeiro. Disponível no site do TICCIH: http://www.mnactec.cat/ticcih/pdf/NTagilPortuguese.pdf, acesso em 17.01.2010.

${ }^{20}$ Relatório Técnico. IPHAN. Processo de Tombamento no 1144-T-85, p.23.
} 
As considerações colocadas pelo impugnante para o pretendido tombamento da Fábrica Santa Amélia, justifica o raciocínio sobre o qual se baseia a opinião pública a respeito do ato de tombamento, e mais ainda relativo ao patrimônio industrial:

a) São Luiz já tem, tombados, exemplares mais que suficientes de prédios do padrão arquitetônico em questão, não se justificando obstaculizar o notório surto de desenvolvimento da cidade (grifo nosso), já carente de área como a ocupada pelo imóvel, com o dispensável tombamento.

b) Tendo cessado suas atividades industriais há mais de vinte anos (grifo do autor), já não existem no imóvel qualquer resquício das instalações e maquinaria, que, deteriorada, foi alienada como sucata.

c) Nem possui o Maranhão parque industrial que justifique a preservação de imóvel de medíocre, senão nenhum interesse histórico (grifo nosso).

Pelas razões acima, [...] espera e requer o impugnante que não prospere o malsinado tombamento ${ }^{21}$.

Essa primeira contestação foi encaminhada pela oponente sem ter vistas do processo, devido a erro de localização do prédio no pedido inicial do tombamento. Esse fato devolveu à requerente o prazo de impugnação, no qual, após dar vistas ao processo, a proprietária do imóvel dá continuidade à oposição, agora assinada pelos seus representantes legais:

I. O atento exame dos elementos e informações constantes do processo, longe de vulnerarem as razões alinhavadas pela Impugnante, na verdade dão-Ihe sólido alicerce.

II. Com efeito, nem mesmo o compreensível zelo, no caso excessivo, dos que descreveram o imóvel, conseguiu obnubilar o fato de que o imóvel não passa hoje de um grande galpão, já irremediavelmente desfigurado de suas anteriores características, que, de resto, já à época, não primavam pela pureza de estilo.

III. O tombamento de tal imóvel, sobre ser de total desinteresse cultural e artístico, malferindo portanto, se efetivado, o elevado conceito nacional e internacional que, com inteira justiça goza esse colendo órgão, seria verdadeiro crime (grifo do autor) praticado contra o surto de sadio progresso que bafeja São Luiz, carente de áreas livres de tombamentos ou suas ameaças (grifo nosso), para instalação de modernas indústrias que virão empregar grande

\footnotetext{
${ }^{21}$ Primeira Carta de Oposição ao tombamento do Cotonifício Cândido Ribeiro Ltda, pelo Impugnante, Sra. Homera Novaes Cavalcanti, que representa o liquidante da empresa, datada de 20 /11/1985. Processo de Tombamento no 1144-T-85, pp.38-39.
} 
número de pessoas, colaborando para solucionar o grande problema social do desemprego.

IV. A clarividência e patriotismo dos ilustres homens responsáveis pela preservação do patrimônio histórico e artístico nacional, está certa a impugnante, imporá seja indeferida a malsinada pretensão tombatória 22 .

As contra-razões oferecidas pelo departamento jurídico do IPHAN, à impugnação apresentada pela proprietária, reconhece exatamente o problema contestado pela impugnante: o Patrimônio representado pela fábrica Santa Amélia, é entendido, somente, pelo ângulo da propriedade e de sua imobilização no tempo e no espaço.

A impugnante preocupada com o fato da sociedade comercial achar-se dissolvida [...] opõe-se ao pretendido tombamento, pois parece entender que, se consumado, poderia obstaculizar a alienação do bem (grifo nosso), ao término do processo de dissolução.

Cumpre-nos, no entanto, assinalar que o tombamento consiste, apenas, numa limitação administrativa ao exercício do direito de propriedade, através da qual o que se exige é precipuamente a conservação do bem pelo proprietário, conforme preconiza o artigo 17 do Decreto-lei n025/37, sem, contudo, impedí-lo de exercer as faculdades inerentes ao seu título e domínio, tais como, alienar, locar, doar, permutar.

É válido acrescentar, ainda, que, se ultimado o tombamento, ao proprietário em caso de alienação compete oferecer o imóvel preferencialmente à União, aos Estados e aos Municípios, nos termos do disposto no artigo 22 do Decreto-lei $n^{0} 25 / 37^{23}$.

Observamos com nitidez a percepção do proprietário, a cerca da proteção do imóvel através do instituto do tombamento, como obstáculo, não ao seu valor de uso, mas ao seu valor de troca.

Fato esse sublinhado também no relato do Conselheiro Roberto Cavalcanti de Albuquerque ao sugerir que a liquidante não explicita a "razão fundamental de sua impugnação, qual seja, a eventual redução do valor venal do bem, localizado

\footnotetext{
22 Segunda Carta de Oposição ao tombamento do Cotonifício Cândido Ribeiro Ltda, pelo Impugnante, Sra. Homera Novaes Cavalcanti, que representa o liquidante da empresa, datada de 03.03.1986. IPHAN, Processo de Tombamento no 1144-T-85, pp.49-50.

${ }^{23}$ Parecer da Assessoria Jurídica sobre a oposição ao tombamento do Cotonifício Cândido Ribeiro Ltda. IPHAN, Processo de Tombamento no 1144-T-85, pp. 51-52.
} 
na área central da cidade, em rápida expansão, com acelerada valorização imobiliária"24.

O posicionamento do IPHAN, do setor jurídico e do setor técnico, deixa clara a posição do órgão na iniciativa de tombamento do imóvel da Fábrica Santa Amélia: a preocupação com a salvaguarda dos valores de continuidade histórica e de sua apropriação enquanto recurso cultural, não cambiável em moeda. Esse olhar se faz presente na posição da arquiteta Dora Alcântara ao avaliar o pedido de impugnação da proprietária:

O fato de que os núcleos históricos, detentores de documentos urbanos e arquitetônicos de significativo valor, sejam aqueles que passaram pou um processo de estagnação econômica parece ter gerado o conceito de que patrimônio urbano/arquitetônico seja o oposto de progresso. Não está claro que a falta de apreço pelos testemunhos históricos seja um outro aspecto da mesma incúria com que foram tratadas nossas cidades, em nome de um progresso que procurou, a esse título, escamotear a falta de capacitação para planejar os espaços urbanos, face ao crescimento e às transformações político econômicas por que passou o Brasil. Pelo menos o caos urbano das cidades, que "progrediram" despersonalizando-se, deveria dar motivo para reflexão aos que ainda defendem tais conceitos de progresso.

São Luiz é, justamente, um exemplo de cidade a que se ofereceu, a tempo, recursos para uma expansão harmoniosa, permitindo a preservação da área histórica e o simultâneo desenvolvimento de outras para funçõe predominantementes residenciais, ou industriais e portuárias, modernas, por meio da ligação do centro tradicional às margens opostas dos rios Anil e Bacanga, que em grande parte o delimitam. O desenvolvimento dessas novas áreas tem comprovado a validade da solução adotada, oferecendo ainda oportunidade a muitos outros empreendimentos que certamente advirão, à medida em que a situção da crise nacional vá cedendo lugar àquela em que serão sanados os problemas graves com que a presente nos defrontamos, entre eles os sociais de desemprego ${ }^{25}$.

Para concluir, devemos destacar que com a ampliação do conceito de patrimônio histórico para cultural, novos bens culturais ganham notoriedade, como aqueles relacionados à indústria. Esses bens, somados aos poucos

\footnotetext{
${ }^{24}$ Parecer do Relator do Processo de Tombamento das Edificações que abrigaram a Fábrica Santa Amélia, Conselheiro Roberto Cavalcanti de Albuquerque. IPHAN. Processo de Tombamento no 1144-T-85, p.60.

${ }^{25}$ IPHAN. Processo de Tombamento no 1144-T-85, pp.53-54
} 
protegidos desde a criação do IPHAN relacionados a sítios industriais brasileiros, ainda representam uma parcela muito pequena da riqueza e da complexidade dos bens legados pela industrialização no país. Somente ao peso de um esforço intenso na constituição de um acervo de modos de funcionamento, tipologias edilícias, enfim, uma leitura sistemática dos valores pragmáticos do patrimônio cultural legado pela industrialização, será possível ultrapassar a visão estereotipada que ainda é depositada tanto pela sociedade quanto pelos órgãos de preservação patrimonial sobre os bens culturais não tidos como sinônimos do verdadeiro "patrimônio" cultural brasileiro.

Esse trabalho acha-se ainda, em grande medida, por fazer.

\section{Referências Bibliográficas}

CAMPOS, M. H. Farrapos de algodão: observações acerca da economia maranhense na primeira metade do século XX. Revista de Economia Política e História Econômica, São Paulo, pp. 05 - 26, 01 jun. 2008.

ENDERS, Armelle. Les lieus de mémorie dez anos depois. In: Estudos históricos, Rio de Janeiro, vol.6 no11, pp.128-137.

FONSECA, Maria Cecília Londres da. O patrimônio em processo: trajetória da política federal de preservação no Brasil. Rio de Janeiro, Editora UFRJ; MInCIPHAN, 2005.

Instituto do Patrimônio Histórico e Artístico Nacional (IPHAN). Processo de Tombamento no 1144-T-85, Fábrica Santa Amélia, São Luís, Maranhão.

JEUDY, Henri-Pierre. Espelho das cidades. Rio de Janeiro: Casa da Palavra, 2005. KÜHL, Beatriz M. Preservação do Patrimônio Arquitetônico da Industrialização. São Paulo: Ateliê Editorial, 2008.

MENESES, Ulpiano T. Bezerra de. Patrimônio ambiental urbano: do lugar comum ao lugar de todos. Revista C J Arquitetura, Rio de Janeiro, n. 19, pp. 45-46, 1978.

NORA, Pierre. Lieux de mémoire, I-II-III. Paris: Gallimard, "Quarto", 1997. 
REIS FILHO, Nestor Goulart. Quadro da arquitetura no Brasil. São Paulo: Perspectiva, 1998.

RUBINO, Silvana B. As fachadas da história. As origens, a criação e os trabalhos do SPHAN, 1936-1967. 1992. Mestrado em Antropologia Social. IFCH UNICAMP. SANTOS, Cecília H.G.Rodrigues dos. Problema mal posto, problema reposto. In: Nobre, A. L.; Kamita, M.; Leonídio, O.; Conduru, R.. (Org.). Lucio Costa - um modo de ser moderno. São Paulo: Cosac Naify, 2004, pp. 132-145. 